\title{
Introduction to Fast Capitalism 15.1
}

\author{
Timothy W. Luke
}

Since 2005, Fast Capitalism has worked to serve as an academic journal with a political intent. For now thirteen years, fifteen numbers, and nineteen issues (with a 1.2 issue in 2005, a 2.2 issue in 2006, a 5.2 issue in 2009, and an 8.2 issue in 2011), we have been publishing reviewed scholarship and critical essays about the impact of rapidly changing information and communication technologies on self, society and culture in the 21 st century.

As we announced from the outset, we do not pretend an absolute objectivity, given that the work we publish is written from many perspectives with a viewpoint. Our authors examine how heretofore distinct social institutions, such as work and family, education and entertainment, have blurred to the point of near identity in an accelerated, post-Fordist stage of capitalism. And, we launched this project before there were the nearly 2 billion smart phones and over a billion smart tablets operating everyday around the world in 2018.

The scale, scope, and sweep of these means of communication in the existing mode of information makes it difficult for people to shield themselves from subordination and surveillance. The working day continues to expand; there is increasingly less to actually no "down time" anymore. People can "office" anywhere, using laptops, tablets, and other personal mobile devices to stay constantly in touch. But these invasive technologies that tether us to capital and control can also help us resist these tendencies, as we noted during the Great Recession, the "Color Revolutions," the Occupy movements, and Arab Spring uprisings. People use the Internet as a public sphere in which they can express and enlighten themselves as well as organize others; women, especially, manage their families and nurture children from the job site and on the road, perhaps even "familizing" traditionally patriarchal and bureaucratic work relations; information technologies afford connection, mitigate isolation, and have made way for many new social movements from Occupy Wall Street and Black Lives Matter to \#MeToo and March for Our Lives. We are convinced that the best way to study an accelerated media culture and its various political economies and existential meanings is dialectically, with nuance, avoiding sheer condemnation and ebullient celebration. We seek to shape these new technologies and social structures in democratic ways.

We invite contributions on these and related issues. Some papers will stick close to the ground of daily life and politics; others will ascend the heights of theory in order to get the big picture. The work we publish is both disciplinary and interdisciplinary, bridging the social sciences and humanities. Culture and capital are keywords. As we always have been from the beginning, we are also are intensely interested in cities, the built environment and nature, and we encourage people who theorize space and place to submit their work.

With 15.1, we continue this project with an eclectic mix of essays, beginning with Jacobo Bernardini addressing in his "Nomophobia and Digital Natives" the dark sides of smartphone psychological dependence in contemporary Italy, especially the strong correlations between youth apathy and the massive use of new digital technologies. The second piece by Daniel Broudy, "Flags, Anthems, and Free Speech: A Trump White House," addresses the emergent national populist regime and nationalist movement being constructed in the United States around perhaps the world's first full-blown "reality TV" inspired style of daily administration in President Donald Trump's White House. The third article by Sascha Engel poses the challenge of how to go about "Writing Circuit Histories" by delving deeply into software coding practices to contest the predominant linear narrative devices to which semi-human, semimachinic assemblages for high technology work are subject: the narrative of "progress."

The next essay by Yasmin Ibrahim deals with the complexities of "The East as a Theatre House of Suffering: 'Suffering' Scholarship and the Orientalist Bind" in contemporary media studies. For her, "suffering" is a sustained human predicament, but it has been largely consigned to the East/Global South as a collective human role. In turn, 
the right to look and serve as the authoritative voyeur of spectatorship is conferred to the West. She effectively disputes this "East-West" dichotomy in the oeuvre of suffering scholarship. On the one hand, it has created a twofold humanity where one is the bearer of suffering and the other the voyeur or the moral spectator who can accord pity and compassion to the lesser other. And, on the other hand, she notes how the West/Global North is now a key locus of suffering with the war on terror, the plight of displaced populations seeking refuge, and the impact of rapid climate change. The fifth contribution to the issue "Social Movement Uses of Capitalist Infotainment" by JL Johnson is a fascinating evaluation of how different social movements have mobilized techniques from contemporary social media platforms to communicate with issue group organizations supporting the causes of LGBT advancement, food justice, and human rights. The sixth article in this issue by Benjamin Taylor carefully investigates "The Biopolitical Conditions of Sovereign Performativity," arguing that sovereignty never disappears as a force to be confronted in the everyday workings of states and societies. Instead, the contexts within which it is expressed are constantly shifting as the collective practices of spatial mastery change. In turn, the next piece, Jakob Norberg's "The Tragedy of the Commonplace: Clichés in the Age of Copyright," plays with the persistent imageries of overuse and exhaustion, cloaking the concept of the cliché. He illustrates how linguistic statements, as they circulate in everyday usage, can suffer from a "tragedy of the commons," in which any shared meanings inevitably will be degraded without constraints on use by the community that employs them. Finally, in the concluding article, Timothy W. Luke's "Have a Heart for the Holocene: The Politics of Ark Activism, Collaborative Conservation, and Sponsored Survival at Museums" explores how the Anthropocene concept is now proliferating rapidly as a powerful cultural script essentially free from the geoscience underpinnings binding it to the science of geological deep time. As a free-floating narrative that generates its own cause, effect, and context, the Anthropocene has morphed into a fascinating intellectual development as well as an event in the planet's history. This study explores how a number of museums, zoological preserves, and exotic expositions have mobilized its flexible rhetoric in displays about rapid climate change to map out how one might see the interwoven combined demise of the Holocene, or current epoch in deep time, and emergence of the Anthropocene in unique new configurations. Taken together, they could be regarded as the foundations for a global exposition about the Anthropocene epoch in human and natural history.

In addition, as we now look to publishing 16.1 in 2019, I will return, once again, to being "the Co-Editor" of Fast Capitalism at Virginia Tech in Blacksburg rather than "the Editor." And, our current co-editor, David Arditi, in Arlington at the University of Texas (as his colleagues, academic units, and I planned during 2015 in the aftermath of our Founding Editor's, Ben Agger, unexpected and untimely passing) will be taking on the role of "Editor." During the recently concluded academic year, David successfully stood for tenure and promotion in the Department of Sociology at the University of Texas at Arlington. One important result of this decision is David now has the security and seniority of an associate professor to devote more time and energy to managing Fast Capitalism at its home campus as "the Editor" of the journal. Going forward, Fast Capitalism will maintain its other current editorial positions with Coordinating Editor Beth Anne Shelton (University of Texas at Arlington); Senior Editor: Matthew Levy (Portland Community College); Production Editor: Alison Torres Ramos (Southwestern Adventist University, Keene, Texas), and Managing Editor: H. Scott Clemens. 